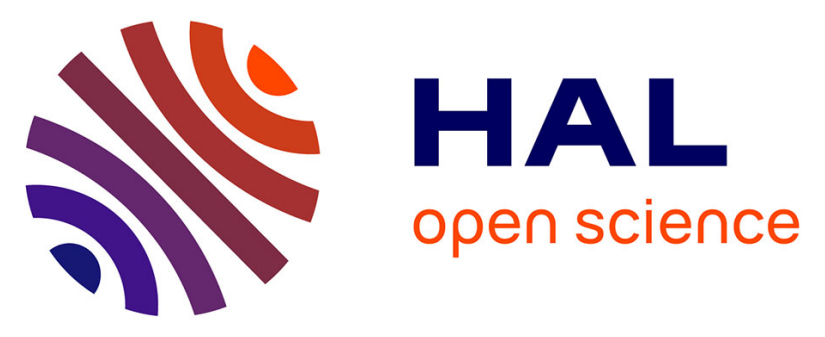

\title{
Occupational exposure to petroleum-based and oxygenated solvents and oral and oropharyngeal cancer risk in men A population-based case-control study in France
}

Christine Barul, Matthieu Carton, Loredana Radoï, Gwenn Menvielle, Corinne Pilorget, Anne-Sophie Woronoff, Isabelle Stücker, Danièle Luce

\section{To cite this version:}

Christine Barul, Matthieu Carton, Loredana Radoï, Gwenn Menvielle, Corinne Pilorget, et al.. Occupational exposure to petroleum-based and oxygenated solvents and oral and oropharyngeal cancer risk in men A population-based case-control study in France. Cancer Epidemiology, 2019, 59, pp.22-28. 10.1016/j.canep.2019.01.005 . hal-02020721

\section{HAL Id: hal-02020721}

https://hal-univ-rennes1.archives-ouvertes.fr/hal-02020721

Submitted on 4 Feb 2020

HAL is a multi-disciplinary open access archive for the deposit and dissemination of scientific research documents, whether they are published or not. The documents may come from teaching and research institutions in France or abroad, or from public or private research centers.
L'archive ouverte pluridisciplinaire HAL, est destinée au dépôt et à la diffusion de documents scientifiques de niveau recherche, publiés ou non, émanant des établissements d'enseignement et de recherche français ou étrangers, des laboratoires publics ou privés. 
Title: Occupational exposure to petroleum-based and oxygenated solvents and oral and oropharyngeal cancer risk in men: a population-based case-control study in France

Christine Barul ${ }^{1}$, Matthieu Carton ${ }^{2}$, Loredana Radoï3,4, Gwenn Menvielle ${ }^{5}$, Corinne Pilorget $^{6,7}$, Anne-Sophie Woronoff ${ }^{8,9}$, Isabelle Stücker ${ }^{3}$, and Danièle Luce $^{1}$; ICARE study group.

\section{Affiliations:}

1. Univ Rennes, Inserm, EHESP, Irset (Institut de Recherche en Santé, Environnement et Travail)-UMR_S 1085, Pointe-à-Pitre, France

2. Institut Curie, PSL Research University, DRCl, Département de Biométrie, Paris, France

3. CESP, Cancer and Environment team, INSERM U1018, Université ParisSud, Université Paris-Saclay, Villejuif, France

4. Faculty of dental surgery, University Paris Descartes, France

5. INSERM, Sorbonne Université, Institut Pierre Louis d'Epidémiologie et de Santé Publique, IPLESP, Department of social epidemiology, F75012 Paris, France

6. The French Public Health Agency, Saint Maurice, France

7. Univ Lyon, Claude Bernard Lyon1 University, Ifsttar, UMRESTTE, UMR T_9405, Lyon, France

8. Doubs and Belfort Territory Cancer Registry, Univ Hosp of Besançon, F25000 Besançon France

9. French network of Cancer registries (Francim), F-31000 Toulouse France

\section{Author's e-mail addresses:}

Christine Barul: christine.barul@inserm.fr Matthieu Carton: matthieu.carton@curie.fr Loredana Radoï:Ioredana.radoi@inserm.fr Gwenn Menvielle:gwenn.menvielle@inserm.fr Corinne Pilorget: corinne.pilorget@univ-lyon1.fr Anne-Sophie Woronoff: asworonoff@chu-besancon.fr Isabelle Stücker: isabelle.stucker@inserm.fr Danièle Luce: daniele.luce@inserm.fr

Corresponding author: Dr Danièle Luce

Address : INSERM U1085-IRSET, Faculté de Médecine, Campus de Fouillole, BP 145, 97154, Pointe-à-Pitre, France

E-mail : daniele.luce@inserm.fr

Word count: 3480 


\section{Abstract}

Objective: To examine the association between occupational exposure to petroleumbased and oxygenated solvents and the risk of oral and oropharyngeal cancer.

Methods: The ICARE study is a large population-based case-control study conducted in France between 2001 and 2007. This present analysis was restricted to men and included 350 and 543 cases of squamous cell-carcinoma of the oral cavity and oropharynx, respectively, and 2,780 controls. Lifetime tobacco, alcohol consumption and complete occupational history were assessed through detailed questionnaires. Job-exposure matrices allowed us to assess occupational exposure to five petroleum-based solvents (white spirits; diesel/fuel oils/kerosene; gasoline; benzene; special petroleum products) and five oxygenated solvents (diethyl ether; tetrahydrofuran; ketones and esters; alcohols; ethylene glycol). Odds-ratios (ORs), adjusted for age, smoking, alcohol consumption and socioeconomic status, and 95\% confidence intervals $(\mathrm{Cl})$ were estimated using unconditional logistic models.

Results: Associations between oral cancer risk and exposure to white spirits and diesel/fuel oils/kerosene were suggested, but there was no exposure-response trend. Concerning exposure to oxygenated solvents, participants with the highest levels of cumulative exposure to diethyl ether had a significant excess risk of oropharyngeal cancer $(\mathrm{OR}=7.78,95 \% \mathrm{Cl} 1.42 ; 42.59 ; \mathrm{p}$ for trend=0.04). Ever exposure to tetrahydrofuran was associated with a borderline significant increased risk of oral cancer (OR=1.87, 95\% $\mathrm{Cl} 0.97 ; 3.61$ ), but no exposure-response trend was observed. Additional adjustments for exposure to other solvents did not substantially change the results. 
Conclusion: Our results do not provide evidence for a major role of petroleumbased and oxygenated solvents in the occurrence of oral and oropharyngeal cancers in men.

Key terms: solvents, epidemiology, case-control study, tumor, occupational health 


\section{Introduction}

In 2012, the age-standardized rate (ASR) for the incidence of oral and pharyngeal cancer was approximately 18.2/100.000 person-years for men in Europe. Western Europe showed the highest ASR for the incidence of oral and pharyngeal cancer, particularly in France where the incidence reached 23.1/100.000 (1). Tobacco and alcohol consumptions are the well-known major risk factors for oral and pharyngeal cancer. Infection by human papillomavirus (HPV) is also associated with an excess risk of oropharyngeal cancer, particularly at the base of tongue and in tonsils (2). The role of occupational exposure in the occurrence of these cancers has been rarely investigated.

Solvents are largely used by workers in several industries. In the workplace, inhalation is the main route of exposure for solvents by which they come into direct contact with the upper respiratory tract. Several studies have investigated the role of occupational exposure to solvents in the occurrence of oral and pharyngeal cancers, but the type of solvent was rarely specified (3). In addition, in most studies, cancers of the oral cavity were grouped with oropharyngeal cancers, or even all pharyngeal cancers, and oropharyngeal cancers have never been studied separately, despite distinct etiological factors. We previously investigated the role of exposure to chlorinated solvents in head and neck cancer risk (4), and found no evidence of an association between these solvents and oral or oropharyngeal cancer. Here, we aimed to examine whether occupational exposure to petroleum-based and oxygenated solvents is associated with oral and oropharyngeal cancer risk in men. 


\section{Methods}

\section{Study design and population}

We used data from the ICARE study, a large French population-based case-control study. All cancers of the respiratory tract were identified from the cancer registries of ten French areas. Concerning head and neck cancers, patients were eligible if they were aged between 18 and 75 years, first diagnosed with a primary, histologically confirmed tumor of the head and neck between 2001 and 2007. Population controls were recruited from the same areas as the cases and selected by incidence density sampling, with frequency-matching for gender and age. Further stratification rendered the controls comparable to the general population in terms of socioeconomic status. Among the 4,047 eligible head and neck cancer cases, 596 (14.7\%) patients could not be located, 299 (7.4\%) deceased before the interview, and $225(5.6 \%)$ could not be interviewed due to poor health. Among the 2,927 cases who were contacted, 2,415 (82.5\%) agreed to participate and were interviewed, on average, within three months of diagnosis. Of 4,673 eligible controls, 4,411 were contacted, and 3555 (80.6\%) agreed to participate. More details about the ICARE study are available elsewhere (5). The present analysis was restricted to men, and to squamous-cell carcinomas of the following sites: oral cavity (International Classification of Diseases for Oncology $3^{\text {rd }}$ revision C00.3-9; C02.0-3; C03.0-1; C03.9, C04.0-1; C04.8-9; C05.0; C06.0-2; C06.8-9), oropharynx (C01.9; C02.4; C05.1-2; C09.0-1; C09.8-9, C10.0-4; C10.8-9). Overall, 893 cases (350 with oral cancer, 543 with oropharyngeal cancer) and 2,780 controls were included in the present study. The study was approved by the Institutional Review Board of the French National Institute of Health and Medical Research (IRB-Inserm, $n^{\circ}$ 01-036), and the French Data Protection Authority (CNIL n 90120). 


\section{Data collection}

Face-to-face interviews were conducted by trained interviewers who administered standardized questionnaires to participants. Sociodemographic characteristics, smoking and alcohol consumption, and a detailed lifetime occupational history covering all jobs held for at least one month, were recorded.

Trained coders, blinded to the case-control status, coded the occupations and industries, according to the International Standard Classification of Occupations (ISCO) (6) and the French Nomenclature of Activities (NAF)(7).

\section{Exposure assessment}

Occupational exposure to five petroleum-based solvents [white spirits, diesel, fuel oils and kerosene, gasoline, benzene, special petroleum products] and five oxygenated solvents [diethyl ether, tetrahydrofuran, ketones and esters, alcohols, ethylene glycol] was assessed by job-exposure matrices (JEMs), developed in the Matgéné program (8). The JEMs provided three indices for each combination of ISCO and NAF codes and each solvent: (i) probability of exposure, expressed as the percentage of exposed workers, (ii) intensity of exposure, and (iii) frequency of exposure as a proportion of the time spent of working. Different categories were used, depending on the solvent, for the three indices (See Additional file 1). Exposure indices were provided for different calendar periods to account for variations due to changes in exposure over time. Then, using occupational lifetime history and the indices of exposure for jobs provided by the JEMs, the following exposure variables were computed for each participant: ever exposure to a specific petroleum-based or oxygenated solvent ('ever' defined as having worked in at least one job with a probability of exposure greater than zero), total duration of exposure, and cumulative exposure index $(\mathrm{CEI})$. The $\mathrm{CEI}$ was the result of summing of the 
product of exposure probability, frequency, and intensity and the duration of each job period, over the entire work history, using the central value of the classes.

Participants never exposed to solvents were the reference category in all analysis. We categorized the duration of exposure according to the approximate tertiles of the distribution among exposed controls: 'short', 'intermediate', and 'long'. CEI was categorized according to the percentiles of the distribution among exposed controls as follows: 'low' $\left(<50^{\text {th }}\right)$, 'medium' $\left(50^{\text {th }}\right.$ to $\left.90^{\text {th }}\right)$, and 'high' $\left(>90^{\text {th }}\right)$.

We also estimated the lifetime prevalence of exposure to the various solvents as the mean of the maximum probability of exposure of each subject over his working life, using the central values of the classes.

\section{Statistical analysis}

Multivariable unconditional logistic regression was used to estimate ORs and $95 \%$ confidence intervals $(\mathrm{Cl})$.

Analyses were adjusted for the age at interview $(<40,40-49,50-59 ; 60-69, \geq 70$ years), residence area, alcohol consumption $(\leq 0.03,0.04-2.00,2.01-4.99,5.00-7.99$, 8.00-11.99, $\geq 12$ glasses/day), smoking status (never; former: time since stopping smoking $>2$ years at the interview for controls/at the diagnosis for cases; current), daily consumption of tobacco (never, 1-10, 11-19, 20-25, > 25 grams/day), duration of tobacco smoking (never, 1-20, 21-30, 31-40, > 40 years), and socioeconomic status, assessed by the occupational class of the longest job held (farmers, selfemployed, managers, intermediate occupations, employees, blue-collar workers). Additional adjustment for asbestos exposure did not modify the ORs and the results presented here are thus not adjusted for asbestos. Tests for linear trends were performed by modelling the median of each category as a continuous variable. 
Each solvent was analyzed separately. We also estimated mutually adjusted ORs in models which included all the petroleum-based and oxygenated solvents, in addition to the main confounders.

We also conducted sensitivity analyses using a different cut-off point for the probability of exposure (probability $>50 \%$ ), in order to increase specificity.

\section{Results}

A total of 3,673 men were included in this study (table 1). The mean age of the subjects with oral and oropharyngeal cancer at diagnosis was of 55.9 and 57.5 years, respectively, whereas the controls were slightly older (58 years). The cases included proportionally more blue-collar workers (oral cancer: $62.6 \%$; oropharyngeal cancer: $65.4 \%$ ) and fewer managers (oral and oropharyngeal cancer: $5.7 \%$ ) than controls, who were composed of $37.9 \%$ blue-collar workers and $19.6 \%$ managers. Moreover, cases were more often smokers and drinkers than controls, as expected. Among controls, the lifetime prevalence of exposure to petroleum-based solvents ranged from $2.5 \%$ for special petroleum products to $14.4 \%$ for white-spirits and diesel/fuel oils/kerosene. Prevalence was in general higher among cases. Lifetime prevalence of exposure to oxygenated solvents in controls ranged from $0.7 \%$ for tetrahydrofuran to $12.9 \%$ for alcohols. Prevalence was higher for cases than controls for exposure to ketones/esters and to tetrahydrofuran. Exposures to the solvents under study were correlated. The stronger correlations were found between exposures to benzene and white spirits $(r=0.62)$, gasoline and diesel/fuel oils/kerosene $(r=0.69)$ and ketones/esters and alcohols ( $r=0.64)$ (see supplemental file A2). 
Table 1. Main characteristics of male cases and controls

\begin{tabular}{|c|c|c|c|c|c|c|}
\hline & \multicolumn{2}{|c|}{$\begin{array}{l}\text { Oral cavity } \\
n=350\end{array}$} & \multicolumn{2}{|c|}{$\begin{array}{c}\text { Oropharynx } \\
n=543\end{array}$} & \multicolumn{2}{|c|}{$\begin{array}{l}\text { Controls } \\
n=2,780\end{array}$} \\
\hline & $\mathbf{n}$ & $\%$ & $\mathbf{n}$ & $\%$ & $\mathbf{n}$ & $\%$ \\
\hline \multicolumn{7}{|l|}{ Age, years } \\
\hline Mean (sd) & $56(8.8)$ & & $57(8)$ & & $58(9.9)$ & \\
\hline$<40$ & 11 & 3.1 & 6 & 1.10 & 76 & 2.7 \\
\hline $40 ; 49$ & 72 & 20.6 & 89 & 16.4 & 555 & 20.0 \\
\hline $50 ; 59$ & 146 & 41.7 & 247 & 45.5 & 825 & 29.7 \\
\hline $60 ; 69$ & 95 & 27.1 & 150 & 27.6 & 939 & 33.8 \\
\hline$\geq 70$ & 26 & 7.4 & 51 & 9.4 & 385 & 13.9 \\
\hline \multicolumn{7}{|l|}{ Socioeconomic status } \\
\hline Farmers & 6 & 1.7 & 14 & 2.6 & 168 & 6.0 \\
\hline Self-employed workers & 21 & 6.0 & 33 & 6.1 & 152 & 5.5 \\
\hline Managers & 20 & 5.7 & 31 & 5.7 & 544 & 19.6 \\
\hline Intermediate occupations & 42 & 12.0 & 50 & 9.2 & 564 & 20.3 \\
\hline Employees & 38 & 10.9 & 56 & 10.3 & 297 & 10.7 \\
\hline Blue collar workers & 219 & 62.6 & 355 & 65.4 & 1053 & 37.9 \\
\hline \multicolumn{7}{|l|}{ Alcohol consumption, glasses/day } \\
\hline$\leq 0.03$ & 18 & 5.1 & 21 & 3.9 & 206 & 7.4 \\
\hline $0.04-2.00$ & 40 & 11.4 & 73 & 13.4 & 1190 & 42.8 \\
\hline $2.01-4.99$ & 95 & 27.1 & 122 & 22.5 & 849 & 30.5 \\
\hline $5.00-7.99$ & 63 & 18.0 & 113 & 20.8 & 305 & 11.0 \\
\hline $8.00-11.99$ & 65 & 18.6 & 84 & 15.5 & 134 & 4.8 \\
\hline$\geq 12.00$ & 60 & 17.1 & 119 & 21.9 & 73 & 2.6 \\
\hline \multicolumn{7}{|l|}{ Smoking status } \\
\hline Never & 13 & 3.7 & 19 & 3.5 & 753 & 27.1 \\
\hline Former $^{1}$ & 61 & 17.4 & 147 & 27.1 & 1271 & 45.7 \\
\hline Current & 276 & 78.9 & 375 & 69.1 & 751 & 27.0 \\
\hline \multicolumn{7}{|l|}{ Lifetime prevalence of exposure } \\
\hline \multicolumn{7}{|l|}{ Petroleum-based solvents } \\
\hline White spirits & & 20.0 & & 20.8 & & 14.4 \\
\hline Diesel. fuel oils and kerosene & & 15.9 & & 15.6 & & 14.4 \\
\hline Gasoline & & 8.4 & & 10.6 & & 8.7 \\
\hline Benzene & & 14.1 & & 14.8 & & 11.7 \\
\hline Special petroleum products & & 2.6 & & 2.2 & & 2.5 \\
\hline \multicolumn{7}{|l|}{ Oxygenated solvants } \\
\hline Diethyl ether & & 0.5 & & 1.3 & & 1.4 \\
\hline Tetrahydrofuran & & 1.7 & & 1.0 & & 0.7 \\
\hline Ketones and esters & & 12.6 & & 12.9 & & 9.5 \\
\hline Alcohols & & 11.6 & & 13.9 & & 12.9 \\
\hline Ethylene glycol & & 5.5 & & 6.4 & & 6.1 \\
\hline
\end{tabular}

1- Time since stopping smoking $>2$ years at the interview for controls/at the diagnosis for cases. 
Associations between occupational exposure to petroleum-based solvents and the risk of oral and oropharyngeal cancer are shown in table 2.

Ever exposure to white spirits was associated with a non-significantly increased risk of oral cancer $(\mathrm{OR}=1.13,95 \% \mathrm{Cl} 0.83 ; 1.53)$, but there was no indication of a doseresponse relationship for duration or cumulative exposure.

Exposure to diesel, and fuel oils and kerosene was also associated with a nonsignificantly elevated risk of oral cancer $(\mathrm{OR}=1.05,95 \% \mathrm{Cl} 0.77 ; 1.43)$, but the increased risk was limited to the shortest duration of exposure $(\mathrm{OR}=1.45,95 \% \mathrm{Cl}$ $0.97 ; 2.18)$ and the lowest level of cumulative exposure $(\mathrm{OR}=1.24,95 \% \mathrm{Cl} 0.86$; 1.79). Exposure to gasoline was associated with a decreased risk of oral $(\mathrm{OR}=0.69$, $95 \% \mathrm{Cl} 0.48 ; 1.00)$ and oropharyngeal cancer $(\mathrm{OR}=0.68,95 \% \mathrm{Cl} 0.51 ; 0.92)$, with negative trends for duration $(p=0.03 ; p<0.01)$ and cumulative exposure $(p=0.10 ; p=$ 0.08). There was no other association between occupational exposure to petroleumbased solvents and the risk of oral and oropharyngeal cancer. 
Table 2. Association between exposure to petroleum-based solvents and risk of oral and oropharyngeal cancer in men

\begin{tabular}{|c|c|c|c|c|c|c|c|c|c|}
\hline & \multicolumn{5}{|c|}{ Oral cavity } & \multicolumn{4}{|c|}{ Oropharynx } \\
\hline & n Co & $\mathrm{n} \mathrm{Ca}$ & $\mathrm{OR}_{1}$ & \multicolumn{2}{|c|}{$[95 \% \mathrm{Cl}]$} & $\mathrm{n} \mathrm{Ca}$ & $\mathrm{OR}_{1}$ & \multicolumn{2}{|c|}{$[95 \% \mathrm{Cl}]$} \\
\hline \multicolumn{10}{|l|}{ White spirits } \\
\hline Never & 1436 & 132 & 1 & \multicolumn{2}{|c|}{ Ref } & 199 & 1 & \multicolumn{2}{|c|}{ Ref } \\
\hline Ever & 1240 & 197 & 1.13 & 0.83 & 1.53 & 306 & 0.99 & 0.76 & 1.28 \\
\hline \multicolumn{10}{|l|}{ Duration of exposure } \\
\hline Short & 489 & 69 & 1.03 & 0.70 & 1.53 & 133 & 0.78 & 0.54 & 1.14 \\
\hline Intermediate & 336 & 59 & 1.25 & 0.82 & 1.92 & 60 & 0.86 & 0.59 & 1.25 \\
\hline Long & 415 & 69 & 1.16 & 0.76 & 1.75 & 112 & 0.71 & 0.50 & 1.02 \\
\hline $\mathrm{p}$ for trend & & & 0.59 & & & & 0.41 & & \\
\hline \multicolumn{10}{|l|}{ CEI } \\
\hline Low & 620 & 86 & 1.15 & 0.80 & 1.66 & 136 & 1.20 & 0.88 & 1.65 \\
\hline Medium & 494 & 89 & 1.10 & 0.75 & 1.60 & 131 & 0.73 & 0.49 & 1.08 \\
\hline High & 126 & 22 & 1.12 & 0.61 & 2.05 & 38 & 0.89 & 0.63 & 1.26 \\
\hline $\mathrm{p}$ for trend & & & 0.84 & & & & 0.74 & & \\
\hline \multicolumn{10}{|c|}{ Diesel, fuel oils and kerosene } \\
\hline Never & 1753 & 183 & 1 & \multicolumn{2}{|c|}{ Ref } & 291 & 1 & \multicolumn{2}{|c|}{ Ref } \\
\hline Ever & 918 & 146 & 1.05 & 0.77 & 1.43 & 212 & 0.78 & 0.60 & 1.01 \\
\hline \multicolumn{10}{|l|}{ Duration of exposure } \\
\hline Short & 309 & 59 & 1.45 & 0.97 & 2.18 & 66 & 0.78 & 0.54 & 1.14 \\
\hline Intermediate & 290 & 39 & 0.95 & 0.60 & 1.51 & 64 & 0.86 & 0.59 & 1.25 \\
\hline Long & 319 & 46 & 0.77 & 0.49 & 1.20 & 81 & 0.71 & 0.5 & 1.25 \\
\hline $\mathrm{p}$ for trend & & & 0.32 & & & & 0.17 & & \\
\hline \multicolumn{10}{|l|}{ CEI } \\
\hline Low & 460 & 74 & 1.24 & 0.86 & 1.79 & 131 & 1.02 & 0.75 & 1.38 \\
\hline Medium & 366 & 62 & 1.03 & 0.69 & 1.53 & 64 & 0.54 & 0.37 & 0.79 \\
\hline High & 92 & 8 & 0.40 & 0.17 & 0.96 & 16 & 0.55 & 0.29 & 1.05 \\
\hline$p$ for trend & & & 0.05 & & & & 0.06 & & \\
\hline \multicolumn{10}{|l|}{ Gasoline } \\
\hline Never & 2161 & 263 & 1 & \multicolumn{2}{|c|}{ Ref } & 388 & 1 & \multicolumn{2}{|c|}{ Ref } \\
\hline Ever & 510 & 66 & 0.69 & 0.48 & 1.00 & 115 & 0.68 & 0.51 & 0.92 \\
\hline \multicolumn{10}{|l|}{ Duration of exposure } \\
\hline Short & 203 & 29 & 0.96 & 0.58 & 1.59 & 51 & 0.86 & 0.57 & 1.30 \\
\hline Intermediate & 97 & 10 & 0.44 & 0.20 & 0.97 & 25 & 0.67 & 0.38 & 1.19 \\
\hline Long & 210 & 26 & 0.61 & 0.36 & 1.04 & 38 & 0.52 & 0.34 & 0.81 \\
\hline $\mathrm{p}$ for trend & & & 0.03 & & & & $<0.01$ & & \\
\hline \multicolumn{10}{|l|}{ CEI } \\
\hline Low & 257 & 33 & 0.70 & 0.44 & 1.11 & 70 & 0.83 & 0.57 & 1.19 \\
\hline Medium & 205 & 28 & 0.79 & 0.47 & 1.33 & 36 & 0.52 & 0.33 & 0.83 \\
\hline High & 48 & 4 & 0.33 & 0.09 & 1.15 & 8 & 0.49 & 0.20 & 1.20 \\
\hline $\mathrm{p}$ for trend & & & 0.10 & & & & 0.08 & & \\
\hline
\end{tabular}




\begin{tabular}{|c|c|c|c|c|c|c|c|c|c|}
\hline \multirow{2}{*}{ Benzene } & \multicolumn{5}{|c|}{ Oral cavity } & \multicolumn{4}{|c|}{ Oropharynx } \\
\hline & \multirow{3}{*}{$\begin{array}{c}\text { n Co } \\
2120 \\
552\end{array}$} & \multirow{3}{*}{$\begin{array}{c}\text { n Ca } \\
256 \\
73\end{array}$} & \multirow{3}{*}{$\begin{array}{c}\mathbf{O R}_{1} \\
1 \\
0.79\end{array}$} & \multicolumn{2}{|c|}{$[95 \% \mathrm{Cl}]$} & \multirow{3}{*}{$\begin{array}{l}\text { n Ca } \\
386 \\
116\end{array}$} & \multirow{3}{*}{$\begin{array}{c}\mathrm{OR}_{1} \\
1 \\
0.72\end{array}$} & \multicolumn{2}{|c|}{$[95 \% \mathrm{Cl}]$} \\
\hline Never & & & & \multicolumn{2}{|c|}{ Ref } & & & \multicolumn{2}{|c|}{ Ref } \\
\hline Ever & & & & 0.56 & 1.11 & & & 0.54 & 0.95 \\
\hline \multicolumn{10}{|l|}{ Duration of exposure } \\
\hline Short & 232 & 26 & 0.68 & 0.41 & 1.13 & 48 & 0.69 & 0.45 & 1.04 \\
\hline Intermediate & 127 & 19 & 0.91 & 0.49 & 1.68 & 24 & 0.65 & 0.38 & 1.13 \\
\hline Long & 193 & 28 & 0.85 & 0.51 & 1.43 & 44 & 0.80 & 0.52 & 1.22 \\
\hline$p$ for trend & & & 0.42 & & & & 0.19 & & \\
\hline \multicolumn{10}{|l|}{ CEI } \\
\hline Low & 279 & 34 & 0.77 & 0.49 & 1.22 & 59 & 0.84 & 0.58 & 1.22 \\
\hline Medium & 220 & 34 & 0.90 & 0.56 & 1.43 & 44 & 0.57 & 0.37 & 0.87 \\
\hline High & 53 & 5 & 0.42 & 0.13 & 1.34 & 13 & 0.83 & 0.39 & 1.75 \\
\hline$p$ for trend & & & 0.15 & & & & 0.30 & & \\
\hline \multicolumn{10}{|c|}{ Special petroleum products } \\
\hline Never & 2439 & 303 & 1 & \multicolumn{2}{|c|}{ Ref } & 458 & 1 & \multicolumn{2}{|c|}{ Ref } \\
\hline Ever & 234 & 26 & 0.84 & 0.51 & 1.40 & 44 & 0.85 & 0.55 & 1.30 \\
\hline \multicolumn{10}{|l|}{ Duration of exposure } \\
\hline Short & 116 & 13 & 0.75 & 0.37 & 1.48 & 24 & 0.81 & 0.46 & 1.45 \\
\hline Intermediate & 42 & 6 & 1.21 & 0.42 & 3.43 & 9 & 1.16 & 0.48 & 2.82 \\
\hline Long & 76 & 7 & 0.81 & 0.31 & 2.10 & 11 & 0.72 & 0.32 & 1.62 \\
\hline$p$ for trend & & & 0.74 & & & & 0.76 & & \\
\hline \multicolumn{10}{|l|}{ CEI } \\
\hline Low & 118 & 11 & 0.84 & 0.40 & 1.79 & 20 & 0.88 & 0.47 & 1.63 \\
\hline Medium & 93 & 12 & 0.75 & 0.36 & 1.57 & 21 & 0.82 & 0.44 & 1.52 \\
\hline High & 23 & 3 & 1.32 & 0.33 & 5.28 & 3 & 0.82 & 0.21 & 3.27 \\
\hline$p$ for trend & & & 0.74 & & & & 0.51 & & \\
\hline
\end{tabular}

Abbreviations: Ca, cases; Co, controls; CEl, cumulative exposure index;

1-OR adjusted for age at interview, residence area, alcohol consumption, smoking status, frequency and duration of smoking, and socioeconomic status 
Associations between occupational exposure to oxygenated solvents and the risk of oral and oropharyngeal cancer are shown reported in table 3.

Ever exposure to diethyl ether was associated with a non-significantly elevated risk of oropharyngeal cancer $(\mathrm{OR}=1.33,95 \% \mathrm{Cl} 0.10 ; 1.35)$, and the highest ORs were observed for the longest duration $(\mathrm{OR}=2.1995 \% \mathrm{Cl} 0.65 ; 7.39)$ and the highest level of cumulative exposure $(\mathrm{OR}=7.78,95 \% \mathrm{Cl} 1.42 ; 42.59)$, with a significant positive trend for cumulative exposure $(p=0.04)$. Ever exposure to tetrahydrofuran was associated with an excess risk of oral cancer of borderline significance $(\mathrm{OR}=1.87$, $95 \% \mathrm{Cl} 0.97 ; 3.61)$. There were no clear dose-response relationships, the highest ORs were observed for the intermediate categories of duration $(\mathrm{OR}=2.19,95 \% \mathrm{Cl}$ $0.75 ; 6.37)$ and cumulative exposure $(\mathrm{OR}=2.30,95 \% \mathrm{Cl} 0.85 ; 6.21)$. Exposure to tetrahydrofuran was not associated with oropharyngeal cancer. We found no other relevant association between occupational exposure to oxygenated solvents and the risk of oral and oropharyngeal cancer.

Analyses using a more stringent definition of exposure (probability $>50 \%$ ) produced similar results: we found a non-significantly increased risk of oral cavity cancer associated with exposure to tetrahydrofuran $(\mathrm{OR}=1.72,95 \% \mathrm{Cl} 0.69 ; 4.28)$, with no exposure-response trend, a significantly increased risk of oropharyngeal cancer in those exposed to the highest cumulative levels of diethyl ether $(\mathrm{OR}=7.59,95 \% \mathrm{Cl}$ $1.40 ; 41.24)$, and no association with the other solvents (data not shown). 
Table 3. Association between exposure to oxygenated solvents and risk of oral and oropharyngeal cancer in men

\begin{tabular}{cccccccc}
\hline \multicolumn{4}{c}{ Oral cavity } & \multicolumn{3}{c}{ Oropharynx } \\
\hline $\mathrm{n} \mathrm{Co}$ & $\mathrm{n} \mathrm{Ca}$ & $\mathrm{OR}_{1}$ & {$[95 \% \mathrm{Cl}]$} & $\mathrm{n} \mathrm{Ca}$ & $\mathrm{OR}_{1}$ & {$[95 \% \mathrm{Cl}]$} \\
\hline
\end{tabular}

Solvents

Diethyl ether

\begin{tabular}{cccccccccc} 
Never & 2580 & 326 & 1 & \multicolumn{2}{c}{ Ref } & 490 & 1 & & Ref \\
Ever & 90 & 3 & 0.36 & 0.10 & 1.35 & 12 & 1.33 & 0.61 & 2.88
\end{tabular}

Duration of exposure

$\begin{array}{cccccccccc}\text { Short } & 29 & 2 & 0.88 & 0.18 & 4.34 & 6 & 1.53 & 0.51 & 4.61 \\ \text { Intermediate } & 26 & 0 & - & & & 2 & 0.43 & 0.07 & 2.6 \\ \text { Long } & 35 & 1 & 0.43 & 0.04 & 4.23 & 4 & 2.19 & 0.65 & 7.39 \\ \text { p for trend } & & & & 0.57 & & & 0.69 & & \end{array}$

CEI

$\begin{array}{cccccccccc}\text { Low } & 45 & 1 & 0.14 & 0.02 & 1.24 & 8 & 1.28 & 0.47 & 3.48 \\ \text { Medium } & 36 & 2 & 0.92 & 0.19 & 4.43 & 2 & 0.65 & 0.13 & 3.21 \\ \text { High } & 9 & 0 & - & & & 2 & 7.78 & 1.42 & 42.59 \\ \text { p for trend } & & & 0.57 & & & & 0.04 & & \end{array}$

Tetrahydrofuran

\begin{tabular}{cccccccccc} 
Never & 2603 & 312 & 1 & \multicolumn{2}{c}{ Ref } & 486 & 1 & & Ref \\
Ever & 67 & 17 & 1.87 & 0.97 & 3.61 & 16 & 0.91 & 0.47 & 1.78
\end{tabular}

Duration of exposure

$\begin{array}{clllllllll}\text { Short } & 29 & 6 & 1.63 & 0.57 & 4.69 & 5 & 0.70 & 0.23 & 2.12 \\ \text { Intermediate } & 19 & 7 & 2.19 & 0.75 & 6.37 & 6 & 1.14 & 0.37 & 3.54 \\ \text { Long } & 19 & 4 & 1.85 & 0.52 & 6.57 & 5 & 0.99 & 0.30 & 3.29 \\ \text { p for trend } & & & 0.48 & & & & 0.92 & & \end{array}$

CEI

$\begin{array}{cccccccccc}\text { Low } & 35 & 8 & 1.83 & 0.72 & 4.61 & 8 & 1.02 & 0.42 & 2.50 \\ \text { Medium } & 26 & 8 & 2.30 & 0.85 & 6.21 & 7 & 0.98 & 0.33 & 2.89 \\ \text { High } & 6 & 1 & 0.84 & 0.08 & 8.77 & 1 & 0.33 & 0.03 & 3.74 \\ \text { p for trend } & & & 0.52 & & & & 0.45 & & \end{array}$

Ketones and esters

\begin{tabular}{cccccccccc} 
Never & 2055 & 618 & 1 & \multicolumn{2}{c}{ Ref } & 353 & 1 & & Ref \\
Ever & 618 & 91 & 1.00 & 0.72 & 1.38 & 150 & 0.96 & 0.73 & 1.26
\end{tabular}

Duration of exposure

$\begin{array}{clllllllll}\text { Short } & 207 & 29 & 0.82 & 0.50 & 1.35 & 53 & 1.02 & 0.67 & 1.54 \\ \text { Intermediate } & 179 & 29 & 1.17 & 0.69 & 1.96 & 43 & 1.07 & 0.69 & 1.67 \\ \text { Long } & 232 & 33 & 1.06 & 0.65 & 1.73 & 54 & 0.84 & 0.56 & 1.26 \\ \text { p for trend } & & & 0.72 & & & & 0.65 & & \end{array}$

CEI

$\begin{array}{cccccccccc}\text { Low } & 309 & 45 & 1.00 & 0.65 & 1.52 & 78 & 1.14 & 0.80 & 1.62 \\ \text { Medium } & 245 & 36 & 0.93 & 0.59 & 1.49 & 55 & 0.77 & 0.52 & 1.15 \\ \text { High } & 64 & 10 & 1.28 & 0.56 & 2.91 & 17 & 0.98 & 0.49 & 1.96 \\ \text { p for trend } & & & 0.92 & & & & 0.92 & & \end{array}$




\begin{tabular}{|c|c|c|c|c|c|c|c|c|c|}
\hline \multirow{2}{*}{ Alcohols } & \multicolumn{5}{|c|}{ Oral cavity } & \multicolumn{4}{|c|}{ Oropharynx } \\
\hline & \multirow{3}{*}{$\begin{array}{c}\text { n Co } \\
1775 \\
898\end{array}$} & \multirow{2}{*}{$\begin{array}{l}\text { n Ca } \\
232\end{array}$} & \multirow{2}{*}{$\begin{array}{c}\mathbf{O R}_{1} \\
1\end{array}$} & \multicolumn{2}{|c|}{$[95 \% \mathrm{Cl}]$} & \multirow{2}{*}{$\begin{array}{r}\text { n Ca } \\
339\end{array}$} & \multirow{3}{*}{$\begin{array}{c}\text { OR }_{1} \\
1 \\
0.95\end{array}$} & \multicolumn{2}{|c|}{$[95 \% \mathrm{Cl}]$} \\
\hline Never & & & & & & & & & \\
\hline Ever & & & 0.90 & 0.66 & 1.23 & & & 0.74 & 1.23 \\
\hline \multicolumn{10}{|l|}{ Duration of exposure } \\
\hline Short & 289 & 30 & 0.78 & 0.49 & 1.26 & 57 & 0.83 & 0.56 & 1.22 \\
\hline Intermediate & 280 & 38 & 1.03 & 0.65 & 1.65 & 53 & 1.16 & 0.78 & 1.72 \\
\hline Long & 328 & 29 & 0.95 & 0.59 & 1.55 & 56 & 0.94 & 0.64 & 1.38 \\
\hline $\mathrm{p}$ for trend & & & & 0.53 & & & 0.74 & & \\
\hline \multicolumn{10}{|l|}{ CEI } \\
\hline Low & 447 & 47 & 0.99 & 0.66 & 1.48 & 72 & 0.92 & 0.65 & 1.30 \\
\hline Medium & 359 & 40 & 0.79 & 0.51 & 1.23 & 74 & 1.01 & 0.71 & 1.43 \\
\hline High & 91 & 10 & 1.11 & 0.50 & 2.45 & 20 & 0.97 & 0.51 & 1.83 \\
\hline $\mathrm{p}$ for trend & & & & 0.80 & & & 0.76 & & \\
\hline \multicolumn{10}{|l|}{ Ethylene glycol } \\
\hline Never & 2487 & 307 & 1 & & & 466 & 1 & & \\
\hline Ever & 183 & 22 & 0.73 & 0.42 & 1.27 & 36 & 0.68 & 0.43 & 1.08 \\
\hline \multicolumn{10}{|l|}{ Duration of exposure } \\
\hline Short & 68 & 9 & 0.87 & 0.37 & 2.07 & 16 & 0.85 & 0.42 & 1.74 \\
\hline Intermediate & 57 & 9 & 1.10 & 0.45 & 2.67 & 10 & 0.67 & 0.29 & 1.53 \\
\hline Long & 58 & 4 & 0.32 & 0.10 & 1.04 & 10 & 0.54 & 0.25 & $1.1 \mathrm{c}$ \\
\hline$p$ for trend & & & 0.05 & & & & & 0.09 & \\
\hline \multicolumn{10}{|l|}{ CEI } \\
\hline Low & 92 & 15 & 0.81 & 0.41 & 1.62 & 21 & 1.20 & 0.65 & 2.22 \\
\hline Medium & 72 & 5 & 0.24 & 0.07 & 0.85 & 13 & 0.74 & 0.29 & 1.88 \\
\hline High & 19 & 2 & 0.49 & 0.08 & 2.88 & 2 & 0.39 & 0.07 & 2.20 \\
\hline$p$ for trend & & & 0.05 & & & & 0.06 & & \\
\hline
\end{tabular}

Abbreviations: Ca, cases; Co, controls; CEl, cumulative exposure index;

1-OR adjusted for age at interview, residence area, alcohol consumption, smoking status, frequency and duration of smoking, and socioeconomic status 
Mutually adjusted ORs are shown in table 4. Adjustment for exposure to other solvents did not markedly modify the results. When all solvents were included in the model, the ORs associated with exposure to diesel, and fuel oils and kerosene for oral cancer increased to borderline significance $(\mathrm{OR}=1.35,95 \% \mathrm{Cl} 0.92 ; 1.99)$, but there was no evidence of a trend cumulative exposure. The estimates remained virtually unchanged for white spirits and tetrahydrofuran. Considering the confounding effects of exposure to other solvents in the development of oropharyngeal cancer increased the ORs associated with ever exposure to white spirits $(\mathrm{OR}=1.15,95 \% \mathrm{Cl} 0.84 ; 1.59)$, ketones and esters $(\mathrm{OR}=1.35,95 \% \mathrm{Cl} 0.84$; 2.17) and diethyl ether $(\mathrm{OR}=1.48,95 \% \mathrm{Cl} 0.66 ; 3.35)$. No exposure-response trend was apparent for white spirits and ketones and esters. The OR associated with the highest level of cumulative exposure to diethyl ether remained significantly elevated. 
Table 4. Association between exposure to petroleum-based and oxygenated solvents and risk of oral and oropharyngeal cancer in men, with additional adjustment for exposure to all solvents

\begin{tabular}{|c|c|c|c|c|c|c|}
\hline & \multicolumn{3}{|c|}{ Oral cavity } & \multicolumn{3}{|c|}{ Oropharynx } \\
\hline Exposure & \multicolumn{3}{|c|}{$\mathrm{OR}_{1}[95 \% \mathrm{Cl}]$} & \multicolumn{3}{|c|}{$\mathrm{OR}_{1}[95 \% \mathrm{Cl}]$} \\
\hline \multicolumn{7}{|c|}{ Petroleum-based solvents } \\
\hline \multicolumn{7}{|l|}{ White spirits } \\
\hline Ever & 1.16 & 0.79 & 1.69 & 0.88 & 0.63 & 1.24 \\
\hline \multicolumn{7}{|l|}{ CEI } \\
\hline Low & 1.22 & 0.83 & 1.80 & 1.11 & 0.79 & 1.55 \\
\hline Medium & 1.15 & 0.73 & 1.80 & 1.13 & 0.76 & 1.68 \\
\hline High & 0.99 & 0.41 & 2.39 & 1.11 & 0.54 & 2.30 \\
\hline$p$ for trend & 0.25 & & & 0.99 & & \\
\hline \multicolumn{7}{|c|}{ Diesel, fuel oils and kerosene } \\
\hline Ever & 1.35 & 0.92 & 1.99 & 0.88 & 0.63 & 1.24 \\
\hline \multicolumn{7}{|l|}{ CEI } \\
\hline Low & 1.40 & 0.93 & 2.09 & 1.10 & 0.78 & 1.56 \\
\hline Medium & 1.64 & 1.02 & 2.66 & 0.60 & 0.38 & 0.95 \\
\hline High & 0.99 & 0.27 & 3.65 & 0.61 & 0.22 & 1.74 \\
\hline $\mathrm{p}$ for trend & 0.22 & & & 0.09 & & \\
\hline \multicolumn{7}{|l|}{ Gasoline } \\
\hline Ever & 0.60 & 0.37 & 0.98 & 0.75 & 0.50 & 1.13 \\
\hline \multicolumn{7}{|l|}{ CEI } \\
\hline Low & 0.51 & 0.31 & 0.86 & 0.92 & 0.60 & 1.41 \\
\hline Medium & 0.63 & 0.28 & 1.39 & 0.50 & 0.24 & 1.04 \\
\hline High & 0.59 & 0.05 & 6.31 & 0.25 & 0.04 & 1.44 \\
\hline$p$ for trend & 0.58 & & & 0.72 & & \\
\hline \multicolumn{7}{|l|}{ Benzene } \\
\hline Ever & 0.94 & 0.58 & 1.54 & 0.74 & 0.49 & 1.10 \\
\hline \multicolumn{7}{|l|}{ CEI } \\
\hline Low & 0.89 & 0.50 & 1.59 & 0.97 & 0.59 & 1.59 \\
\hline Medium & 1.15 & 0.49 & 2.72 & 0.72 & 0.35 & 1.51 \\
\hline High & 0.91 & 0.12 & 7.02 & 2.47 & 0.58 & 10.55 \\
\hline$p$ for trend & 0.73 & & & 0.88 & & \\
\hline \multicolumn{7}{|c|}{ Special petroleum products } \\
\hline Ever & 0.82 & 0.45 & 1.51 & 0.83 & 0.50 & 1.38 \\
\hline \multicolumn{7}{|l|}{ CEI } \\
\hline Low & 0.66 & 0.30 & 1.46 & 0.87 & 0.45 & 1.71 \\
\hline Medium & 0.76 & 0.33 & 1.72 & 0.87 & 0.43 & 1.76 \\
\hline High & 1.31 & 0.25 & 6.84 & 1.04 & 0.21 & 5.23 \\
\hline$p$ for trend & 0.41 & & & 0.22 & & \\
\hline
\end{tabular}




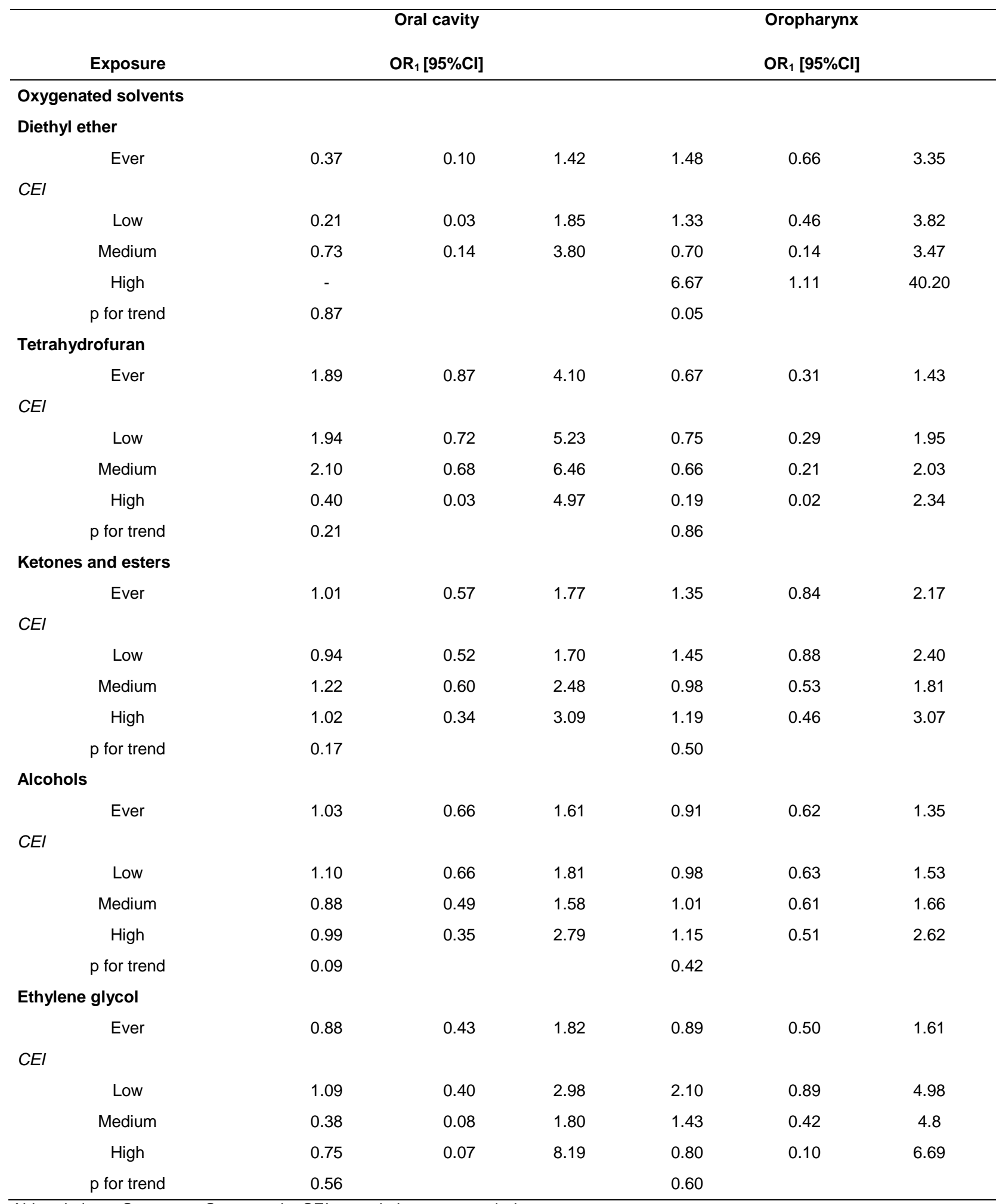

Abbreviations: Ca, cases; Co, controls; CEl, cumulative exposure index

1-OR adjusted for age at interview, residence area, alcohol consumption, smoking status, frequency and duration of smoking, socioeconomic status, and exposure to other solvents 


\section{Discussion}

We found no clear association between oral or oropharyngeal cancer and exposure to the solvents under study. However, our findings suggest an excess risk of oral cancer in men exposed to tetrahydrofuran, as well as an increased risk of oropharyngeal cancer among men exposed to diethyl ether. Few studies have investigated associations between specific solvents and oral and oropharyngeal cancer risk. Several studies have examined the association between occupational exposure to the generic category of solvents and oral or pharyngeal cancer risk (912) but the results were inconsistent. Furthermore, most studies grouped cancers of the oral cavity with oropharyngeal cancers, or all pharyngeal cancers. Therefore, comparisons with our results are limited. In a case-control study in Puerto-Rico (9), exposure to solvents, based on a JEM, was associated with a significant increased risk of oral or pharyngeal cancer, with an exposure-response trend. In three other studies (10-12), exposure to solvents in general, assessed by a JEM in two studies $(10,12)$ and by questionnaire in another (11) was not associated with oral or oropharyngeal cancer. In a cohort of Finns, in which exposures were derived from a national JEM (FINJEM), Tarvainen et al. (13) reported significantly elevated standardized incidence ratios for cancer of the mouth and pharynx in those exposed to the highest levels of "aliphatic and alicyclic hydrocarbon solvents" and "aromatic hydrocarbon solvents". These categories overlap with those of the petroleum-based solvents used in our study. In the same study, the authors found no excess risk in the category "other organic solvents", which included mainly alcohols, ketones, esters, and glycol ethers (13). No study has previously examined the association of occupational exposure to tetrahydrofuran with the risk of oral and oropharyngeal cancers. Tetrahydrofuran has been classified as possibly carcinogenic to humans 
because of sufficient evidence in animals but there is no data in humans (14). We recently reported an association between exposure to tetrahydrofuran and hypopharyngeal cancer, and, to a lesser extent, laryngeal cancer (15). Exposure to tetrahydrofuran was also associated with an increased risk of head and neck cancer in women (16). Here, the association with tetrahydrofuran was limited to oral cancer and we found no association with oropharyngeal cancer. The association between exposure to tetrahydrofuran and oral cancer persisted after adjustment for exposure to other solvents. However, there was no clear trend for duration or cumulative levels of exposure. The potential effect of tetrahydrofuran on the upper respiratory tract requires further investigation.

The carcinogenic potential of exposure to diethyl ether in humans or animals has not been previously evaluated, and results of in vitro genotoxicity tests have been mostly negative (17). Diethyl ether has not been evaluated by the International Agency for Research on Cancer, and volatile anesthetics, including diethyl ether, were evaluated as a group and considered not classifiable in terms of their carcinogenicity to humans (18).Here, we found a significantly increased risk of oropharyngeal cancer for the highest level of cumulative exposure, with a significant trend. No such association has been observed in women (16), and the findings in men, based on a small number of exposed subjects, may be due to chance.

Several limitations of our study have to be considered in interpreting the results. First, JEMs generate systematic misclassifications because they do not consider the heterogeneity of tasks within the same job title. Consequently, a non-differential misclassification bias occurred, which generally results in a biased estimation of the OR towards the null hypothesis for dichotomous exposures, but may also alter doseresponse trends for multilevel exposure variables (19). We do not know the 
magnitude of misclassification in the present study. However, we believe that the methods used for the construction of the JEMs resulted in quite reliable exposure estimates. The JEMs were developed by experienced industrial hygienists, specifically for the French population. Exposure indices were estimated for combinations of occupation and activity, which allows providing refined estimates for occupations with significant between-industry variation, and for different periods, in order to take into account variations in exposure over time, due to changes in raw materials, techniques, working conditions, and regulations. For solvents, exposure estimates were based on more than 300,000 measurements performed in France, on numerous data from technical organizations, as well as more than 50,000 job descriptions from French epidemiological studies (8). Nevertheless, some degree of nondifferential misclassification is unavoidable, and may partly explain our negative results. Second, although we adjusted the analyses for the main risk factors of oral and pharyngeal cancer, there may be residual confounding factors. Information on oral hygiene and diet was, for example not available in our study. We adjusted for socioeconomic status which may partially control for unmeasured behavioral factors, such as diet and oral hygiene. In particular, in our study, information on HPV infection, a risk factor of growing importance for oropharyngeal cancer, was not available. However, HPV is unlikely to be associated with exposure to solvents, although it could be indirectly linked to occupational exposure through socioeconomic status and sexual behaviors. Again, a possible confounding effect of HPV infection may be accounted for by adjustment for socioeconomic status. Furthermore, a comparison of incidence trends between potentially HPV-related and HPV-unrelated head and neck cancers in France suggests that the increasing incidence of head and neck cancers due to HPV infection was limited to the most recent period, especially 
for men. During period of inclusion of the ICARE study, the proportion of head and neck cancers in men attributable to oral HPV infection was probably very low (20). Several strengths reinforce the robustness of our results. A major advantage of JEMs is that they assign exposures in an automatic and reproducible way, irrespective of disease status, thus reducing the risk of recall and reporting bias. Selection bias is also likely to have been minimal. The collaboration with the French network of cancer registries allowed a nearly complete identification of eligible cases, and the distribution of the included cases by age and cancer site was close to that generally observed in France (21). Controls were comparable to the general population in terms of socioeconomic status and prevalence of tobacco smoking and alcohol drinking. In addition, the lifetime prevalence of exposure to petroleum-based and oxygenated solvents in controls was similar to that observed in a representative sample of the French male population (8). Due to the large number of participants the statistical power was sufficient to detect moderate associations. Furthermore, we distinguished between oral and oropharyngeal cancer in the analyses. The quality of the occupational data in the ICARE study can be considered to be good. We were able to investigate occupational exposure to various petroleum-based and oxygenated solvents, some which have never been previously examined in relation to their potential carcinogenicity in humans, and to perform exposure-response analyses.

\section{Conclusion}

Overall, our findings suggest a minimal role, if any, of occupational exposure to petroleum-based or oxygenated solvents in the occurrence of oral and oropharyngeal cancers in men. 


\section{List of references}

1. Ferlay J, Steliarova-Foucher E, Lortet-Tieulent J, Rosso S, Coebergh JWW, Comber $\mathrm{H}$, et al. Cancer incidence and mortality patterns in Europe: Estimates for 40 countries in 2012. Eur. J. Cancer . 2013;49(6):1374-403.

2. International Agency for Research on Cancer, editor. IARC monographs on the evaluation of carcinogenic risks to humans, volume 90 , Human papillomaviruses: this publication represents the views and expert opinions of an IARC Working Group on the Evaluation of Carcinogenic Risks to Humans, which met in Lyon, 15 - 22 February 2005. Lyon: IARC; 2007.

3. Paget-Bailly S, Cyr D, Luce D. Occupational exposures to asbestos, polycyclic aromatic hydrocarbons and solvents, and cancers of the oral cavity and pharynx: a quantitative literature review. Int. Arch. Occup. Environ. Health . 2012;85(4):341-51.

4. Barul C, Fayossé A, Carton M, Pilorget C, Woronoff A-S, Stücker I, et al. Occupational exposure to chlorinated solvents and risk of head and neck cancer in men: a population-based case-control study in France. Environ. Health . 2017;16(1).

5. ICARE study group, Luce D, Stücker I. Investigation of occupational and environmental causes of respiratory cancers (ICARE): a multicenter, populationbased case-control study in France. BMC Public Health . 2011;11(1).

6. International Labour Office. International Standard Classification of Occupations (ISCO). 1968.

7. Institut National de la Statistique et Des Etudes Economiques. Définitions et méthodes - Nomenclature d'activités française. Paris, France; 2000.

8. Fevotte J, Dananche B, Delabre L, Ducamp S, Garras L, Houot M, et al. Matgene: A Program to Develop Job-Exposure Matrices in the General Population in France. Ann. Occup. Hyg. . 2011;55(8):865-78.

9. Coble JB, Brown LM, Hayes RB, Huang W-Y, Winn DM, Gridley G, et al. Sugarcane Farming, Occupational Solvent Exposures, and the Risk of Oral Cancer in Puerto Rico: J. Occup. Environ. Med. . 2003;45(8):869-74.

10. Purdue MP, Järvholm B, Bergdahl IA, Hayes RB, Baris D. Occupational exposures and head and neck cancers among Swedish construction workers. Scand. J. Work. Environ. Health . 2006;32(4):270-5.

11. Schildt EB, Eriksson M, Hardell L, Magnuson A. Occupational exposures as risk factors for oral cancer evaluated in a Swedish case-control study. Oncol. Rep. . 1998;6(2):317-20.

12. Merletti F, Boffetta P, Ferro G, Pisani P, Terracini B. Occupation and cancer of the oral cavity or oropharynx in Turin, Italy. Scand. J. Work. Environ. Health . 1991;17(4):248-54. 
13. Tarvainen L, Kyyronen P, Kauppinen T, Pukkala E. Cancer of the mouth and pharynx, occupation and exposure to chemical agents in Finland [in 1971-95]: Cancer of the Mouth and Pharynx and Occupation. Int. J. Cancer . 2008 Aug 1;123(3):653-9.

14. Grosse Y, Loomis D, Guyton KZ, El Ghissassi F, Bouvard V, Benbrahim-Tallaa $\mathrm{L}$, et al. Some chemicals that cause tumours of the urinary tract in rodents. Lancet Oncol. . 2017;18(8):1003-4.

15. Barul C, Carton M, Radoï L, Menvielle G, Pilorget C, Bara S, et al. Occupational exposure to petroleum-based and oxygenated solvents and hypopharyngeal and laryngeal cancer in France: the ICARE study. BMC Cancer . 2018 Apr 5;18(1):388.

16. Carton M, Barul C, Menvielle G, Cyr D, Sanchez M, Pilorget C, et al. Occupational exposure to solvents and risk of head and neck cancer in women: a population-based case-control study in France. BMJ Open [Internet] . 2017 [cited 2017 Apr 24];7(1). Available from: http://bmjopen.bmj.com/content/7/1/e012833.abstract

17. National Center for Environmental Assessment Office of Research and Development. Provisional peer reviewed toxicity values for ether (diethyl ether) (CASRN 60-29-7). EPA690R09022F Final [Internet] U.S Environmental Protection Agency (EPA). Cincinnati; 2009; Available from: https://cfpub.epa.gov/ncea/pprtv/recordisplay.cfm?deid=338940

18. IARC Working Group. IARC monographs on the evaluation of the carcinogenic risk of chemicals to man: cadmium, nickel, some epoxides, miscellaneous industrial chemicals and general consideration on volatile anaesthetics. IARC Monogr. Eval. Carcinog. Risk Chem. Man . 1976;11:1-293.

19. Blair A, Stewart P, Lubin JH, Forastiere F. Methodological issues regarding confounding and exposure misclassification in epidemiological studies of occupational exposures. Am. J. Ind. Med. . 2007;50(3):199-207.

20. Jéhannin-Ligier K, Belot A, Guizard A-V, Bossard N, Launoy G, Uhry Z, et al. Incidence trends for potentially human papillomavirus-related and -unrelated head and neck cancers in France using population-based cancer registries data: 1980-2012: Incidence trends for potentially human papillomavirus-related and unrelated head and neck cancers in France. Int. J. Cancer . 2017;140(9):20329.

21. Ligier K, Belot A, Launoy G, Velten M, Bossard N, Iwaz J, et al. Descriptive epidemiology of upper aerodigestive tract cancers in France: Incidence over 1980-2005 and projection to 2010. Oral Oncol. . 2011;47(4):302-7. 


\section{Abbreviations}

$\mathrm{OR}=$ odds-ratio; $\mathrm{Cl}=$ confidence interval; $\mathrm{CEI}=$ Cumulative Exposure Index; $\mathrm{HPV}=$ Human papilloma virus

\section{Acknowledgements}

The authors thank all members of the MatGéné working group from Santé Publique France and, in particular, Ms Brigitte Dananché for providing job-exposure matrices.

Members of ICARE Study Group: Anne-Valérie Guizard (Registre des cancers du Calvados, France); Arlette Danzon, Anne-Sophie Woronoff (Registre des cancers du Doubs, France); Michel Velten (Registre des cancers du Bas-Rhin, France); Antoine Buemi, Émilie Marrer (Registre des cancers du Haut-Rhin, France); Brigitte Trétarre (Registre des cancers de l'Hérault, France); Marc Colonna, Patricia Delafosse (Registre des cancers de I'Isère, France); Paolo Bercelli, Florence Molinié (Registre des cancers de Loire-Atlantique-Vendée, France); Simona Bara (Registre des cancers de la Manche, France); Bénédicte Lapotre-Ledoux, Nicole Raverdy (Registre des cancers de la Somme, France); Sylvie Cénée, Oumar Gaye, Florence Guida, Farida Lamkarkach, Loredana Radoï, Marie Sanchez, Isabelle Stücker (INSERM, Centre for research in Epidemiology and Population Health (CESP), U1018, Environmental Epidemiology of Cancer Team, Villejuif, France); Matthieu Carton, Diane Cyr, Annie Schmaus (Inserm Epidemiologic Cohorts Unit-UMS 011 INSERMUVSQ, Villejuif, France); Joëlle Févotte (University Lyon 1, UMRESTTE, Lyon, France); Corinne Pilorget (French Public Health Agency, Department of Occupational Health, Saint Maurice, France); Gwenn Menvielle (Sorbonne Universités, UPMC Univ Paris 06, INSERM,IPLESP UMRS 1136, Paris, France) ; Danièle Luce (INSERM U 1085-IRSET, Pointe-à-Pitre, France).

\section{Funding}

The ICARE study was funded by the French National Research Agency (ANR); French National Cancer Institute (INCA); French Agency for Food, Environmental and Occupational Health and Safety (ANSES); French Institute for Public Health Surveillance (InVS); Fondation pour la Recherche Médicale (FRM); Fondation de France; Fondation ARC pour la Recherche sur le Cancer; Ministry of Labour (Direction Générale du Travail); Ministry of Health (Direction Générale de la Santé).

\section{Declarations}

\section{Ethics approval and consent to participate}

Institutional Review Board of the French National Institute of Health and Medical Research (IRB-Inserm, number 01-036) and the French Data Protection Authority (CNIL number 90 120). Each participant gave a written consent 


\section{Supplemental files}

Supplemental file A.1. Categories of exposure indices

Supplemental file A.2. Correlogram between cumulative exposures to solvents 